\title{
Analisa Sebaran Suhu Permukaan Laut Berdasarkan Citra Landsat-8 TIRS di Sekitar Outfall PLTU Tarahan Lampung Selatan
}

\author{
Muhammad Bani Putra Utama1*, Gentur Handoyo ${ }^{1}$, Heryoso Setiyono ${ }^{1}$, Dwi Haryo \\ Ismunarti $^{1}$, dan Agus Anugroho Dwi Suryoputro ${ }^{1}$
}

\author{
Departemen Oseanografi, Fakultas Perikanan dan Ilmu Kelautan, Universitas Diponegoro \\ Jl. Prof. H. Sudarto, SH, Tembalang Semarang. 50275 Telp/fax (024)7474698 \\ *Email: Baniutama@gmail.com
}

\begin{abstract}
Abstrak
PLTU Tarahan Lampung Selatan menggunakan air laut sebagai air pendingin dalam kegiatan operasionalnya. Kegiatan tersebut menghasilkan limbah air panas yang berhubungan langsung dengan perairan, sehingga dapat mengakibatkan berubahnya suhu permukaan laut di perairan sekitarnya. Penelitian ini bertujuan untuk mengetahui sebaran horizontal limbah air panas di perairan laut sekitar outfall PLTU Tarahan Lampung Selatan. Data yang digunakan dalam penelitian ini meliputi Citra Landsat 8 TIRS, suhu permukaan laut lapangan dan arus permukaan laut lapangan, peta bathimetri yang diterbitkan oleh Pushidrosal, pasang surut yang diterbitkan oleh BIG yang diunduh pada laman http://ina-sealevelmonitoring.big.go.id dan peta RBI yang diterbitkan oleh BIG. Pengambilan data lapangan sebanyak 15 titik untuk mengetahui akurasi data citra dengan pengukuran lapangan. Hasil penelitian menunjukkan bahwa adanya kenaikan suhu permukaan laut oleh limbah air panas PLTU Tarahan Lampung Selatan sebesar $4^{\circ} \mathrm{C}$ dari suhu rata-rata laut di daerah outfall. Pola persebaran suhu permukaan laut membentuk setengah busur dengan luasan sebesar 39 hektar. Suhu tertinggi sebesar $33,5^{\circ} \mathrm{C}$ yang berada di dekat outfall dan terendah sebesar $29,4^{\circ} \mathrm{C}$ dan bergerak menuju arah tenggara dari outfall.
\end{abstract}

Kata kunci : Suhu Permukaan Laut, Landsat 8 TIRS, Sebaran Limbah Air Panas, PLTU Tarahan Lampung Selatan

\begin{abstract}
The Steam Electricity Power Plant Tarahan South Lampung uses sea water for cooling water in its operational activities. The activity produces hot water waste that is directly related to the waters, so that it can lead to increased sea surface temperatures in the waters. Data used in this study include Landsat 8 TIRS imagery, field sea surface temperature and field sea surface currents, bathymetry maps published by Pushidrosal, tides data published by BIG which downloaded on the page http://ina-sealevelmonitoring.big.go.id and maps of the RBI from BIG. Field data capture as much as 15 points to know the accuracy of image data with measurement field. The results obtained from the research showed a rise in sea surface temperature of $4^{\circ} \mathrm{C}$ than the average temperature of the sea around the outfall. The distribution pattern of sea surface temperature forms a half arc with an area of 39 hectares. The highest temperature was $33.5^{\circ} \mathrm{C}$ which is near the outfall and the lowest was $29.4^{\circ} \mathrm{C}$ which is at the farthest point. The pattern of sea surface temperature difstribution was moving towards the Southeast from the outfall.
\end{abstract}

Keywords : Sea Surface Temperature, Landsat 8 TIRS, Distribution of Hot Water Waste The Steam Electricity Power Plant Tarahan South Lampung

\section{PENDAHULUAN}

PLTU dalam kegiatan operasionalnya memerlukan air laut yang digunakan untuk mendinginkan uap air setelah menggerakkan turbin di kondensor. Air laut hasil pengolahan tersebut kemudian dialirkan kembali ke laut dengan suhu relatif tinggi dari suhu perairan yang disebut sebagai limbah air panas. Limbah air panas ini mengakibatkan kenaikan suhu di sekitar daerah ujung pipa dari suhu perairan normal serta mempengaruhi ekosistem perairan, seperti kualitas air dan sirkulasi air lokal (Wibowo, 2012). 
Permasalahan utama kegiatan PLTU ini adalah suhu air buangan dari sistem pendingin yang jauh lebih tinggi dari suhu perairan di sekitarnya. Umumnya suhu air buangan tersebut dapat mencapai $40{ }^{\circ}$ C. Peraturan Menteri Negara Lingkungan Hidup No. 8 Tahun 2009 tentang Baku Mutu Air Limbah Bagi Usaha dan atau Kegiatan Pembangkit Listrik Tenaga Termal dinyatakan bahwa pembuangan limbah panas ke badan air tidak boleh melebihi $40^{\circ} \mathrm{C}$. Air bahang yang mempunyai suhu relatif tinggi akan mempengaruhi perubahan suhu permukaan laut dan kestabilan ekosistem di wilayah perairan sekitarnya.

Pemantauan atau (monitoring) kualitas perairan dilakukan untuk memastikan suhu di sekitar perairan outfall masih berada dalam batas yang wajar. Pemantauan kualitas perairan dilakukan dengan pengamatan langsung dengan mengambil suhu sampel permukaan laut. Selain dengan pengamatan langsung, sebaran suhu limbah air panas dapat dilakukan dengan pendekatan penginderaan jauh Citra Landsat 8 TIRS.

Penelitian ini dilakukan untuk mengetahui sebaran spasial limbah air panas secara horizontal menggunakan Citra Satelit Landsat 8 TIRS. Penelitian ini dilakukan dalam dua tahap, yaitu tahap pertama yaitu pengumpulan data primer dan data sekunder pada bulan Januari - Mei 2019. Tahap kedua yaitu melakukan ground check pada tanggal 10 Mei 2019. Lokasi penelitian ini dilakukan di perairain laut PLTU Tarahan Lampung Selatan yang disajikan pada Gambar 1.

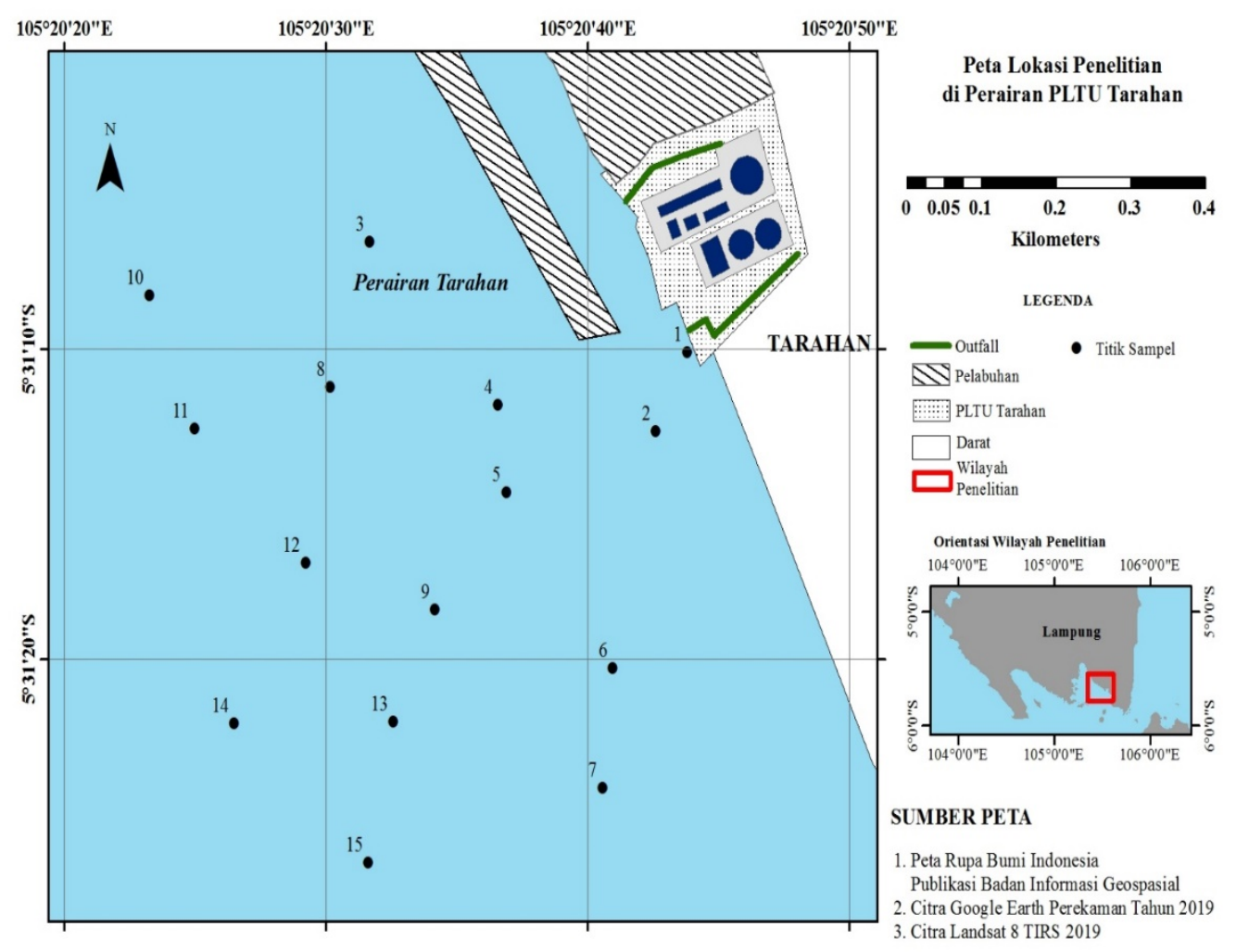

Gambar 1. Peta lokasi penelitian di PLTU Tarahan Lampung Selatan

\section{MATERI DAN METODE}

Materi penelitian ini meliputi data utama dan data pendukung. Data utama terdiri dari Citra Satelit Landsat-8 Path/Row : 123/64 waktu perekaman Mei 2019 yang diunduh dari earthexplorer.usgs.gov. Data suhu permukaan laut dan data arus permukaan laut lapangan yang diperoleh dari pengukuran di lapangan pada 10 Mei 2019 pada pukul 14.00 hingga 17.00 WIB di perairan PLTU Tarahan Lampung Selatan yang berjumlah 15 titik. Data pasang surut yang diunduh pada laman http://inasealevelmonitoring.big.go.id daerah Perairan Tarahan yang diambil selama 30 hari yaitu pada tanggal 131 Mei 2019 dan data kedalaman Perairan Selat Sunda. Metode penelitian yang digunakan yaitu metode 
deskriptif, sedangkan metode penentuan lokasi penelitian menggunakan metode purposive sampling, yaitu metode penentuan pengambilan sampel dengan mempertimbangankan beberapa hal. Pertimbangan tersebut berupa data suhu permukaan laut hasil dari pengolahan citra.

\section{Tahap Pengolahan Data Citra Landsat 8 TIRS}

Pemrosesan Citra Satelit Landsat-8 dilakukan untuk memperoleh informasi suhu permukaan laut. Kanal yang digunakan untuk memperoleh nilai adalah kanal 11, merupakan kanal inframerah termal yang memilki panjang gelombang 10,60-11,19 $\mu \mathrm{m}$ (USGS, 2019). Output yang dihasilkan dari Citra Satelit Landsat 8 TIRS berupa warna yang mewakili sebuah nilai suhu permukaan laut yang diakibatkan oleh limbah air panas.

\section{Import Data}

Data citra satelit Landsat- 8 yang masih berupa data mentah harus diolah terlebih dahulu sehingga menjadi data yang lebih informatif dan dapat diinterpretasikan. Langkah pertama dalam mengolah data adalah pemasukan data dalam bentuk Graphics Format Tiff (tif). Pengolahan ini menggunakan perangkat lunak ER Mapper 7 dan menghasilkan data exstension (ers) pada media penyimpan

\section{Koreksi Radiometri dan Koreksi Geometri}

Hasil data yang telah diolah kemudian dikoreksi untuk memperbaiki kontras tiap piksel dari data citra satelit agar sesuai dengan data sebenarnya dengan mempertimbangkan faktor gangguan atmosfer. Koreksi radiometri dilakukan supaya objek yang terekam mudah untuk diinterpretasikan dan sesuai dengan data yang ada di lapangan. Sedangkan koreksi geometri dilakukan untuk menyesuaikan posisi citra dengan koordinat objek di permukaan bumi, yang disebabkan oleh efek rotasi bumi, pergerakan satelit dan lengkung permukaan bumi. Koreksi geometrik terdiri dari dua tahap yaitu tranformasi geometrik dan resampling. Resampling yang digunakan adalah nearest neighbor resampling, sehingga akan mengeliminasi kordinat GCP sampai menghasilkan nilai RMS (Root Mean Square Error) yang lebih kecil dari 1.

\section{Pembatasan Wilayah}

Citra Satelit Landsat-8 yang diunduh berada di tititk Row/Path 123/64 dan merupakan wilayah Lampung yaitu dari Teluk hingga Pantai Timur Lampung dan dari Pulau Sebuku hingga Selat Sunda. Citra yang didapat lebih difokuskan ke objek penelitian yaitu daerah PLTU Tarahan yang berada di daerah pesisir Desa Tarahan dan berada di perairan Teluk Lampung.

\section{Analisis Kuantitatif Citra Landsat Termal}

Analisis kuantitatif dibagi menjadi beberapa tahap untuk memudahkan pengolahan data menggunakan persamaan rumus matematik, antara lain yaitu :

\section{a. Konversi Nilai Digital Menjadi Nilai Radian}

Berikut ini merupakan persamaan yang digunakan untuk mengkonversi nilai digital menjadi nilai radiasi (USGS, 2019):

$L \lambda=(M L x Q c a l)+A L$

Keterangan :

$L \lambda \quad$ : TOA spectral radiance/ radiasi spektral (Watts $/(\mathrm{m} 2 . \operatorname{srad} . \mu \mathrm{m}))$

$M L$ : Band spesifik faktor rescaling perkalian dari metadata (RADIANCE_MULT_BAND_11, dimana 11 adalah nomer band)

$A L$ : Band spesifik faktor rescaling aditif dari metadata (RADIANCE_ADD_BAND_11, dimana 11

adalah nomer band)

Qcal: Produk standar piksel yang dikuantisasi dan dikalibrasi (Digital Number) 


\section{b. Konversi Nilai Radian Menjadi Suhu Radian}

Formulasi untuk mengubah nilai piksel menjadi nilai suhu radiasi yang dapat dihitung berdasarkan nilai radiasi spektral yang sudah diubah kedalam nilai celcius dengan menggunakan persamaan berikut (USGS, 2019):

$\mathrm{T}=\frac{\mathrm{K} 2}{\operatorname{in}\left(\left(\frac{\mathrm{K} 1}{\mathrm{~L} \lambda}\right)+1\right)}-273$

Keterangan :

$\mathrm{T}=$ Suhu Radiasi (Celcius)

K2 $=$ Konstanta Kalibrasi 2 (1282,71 Kelvin)

K1 = Konstanta Kalibrasi 1 (666,09 watts / (meter2.ster. $\mu \mathrm{m})$

$\mathrm{L} \lambda=$ Radiasi Spektral dalam watts / (meter2.ster. tm)

\section{c. Transformasi Suhu Radian Menjadi Suhu Permukaan Laut}

Transformasi nilai suhu radian menjadi nilai suhu permukaan laut dapat dihitung dengan persamaan berikut (Bambang et al., 2011):

$S S T=A T^{3}-B T^{2}+C T-1161,2$

Keterangan :

SST $=$ Sea Surface Temperature / Suhu Permukaan Laut

$\mathrm{A}=0,0684$

$\mathrm{B}=5,3082$

$\mathrm{C}=137,59$

$\mathrm{T}=$ Suhu Radiasi (Celcius)

\section{Tahap Pengolahan Data Hidro-oseanografi}

Data oseanografi terdiri dari suhu permukaan laut, pasang surut, kedalaman perairan dan pasang surut. Data suhu permukaan laut disajikan berbentuk tabel sehingga dapat memudahkan pada tahap validasi data. Data pasang surut dan kedalaman perairan digunakan untuk modeling arus pasang surut dengan pemodelan hidrodinamika arus pasang surut.

\section{Tahap validasi data}

Tahap verifikasi data Citra Satelit Landsat 8 TIRS dengan data hasil pengukuran lapangan, yaitu dengan cara membandingkan nilai suhu permukaan laut pada setiap stasiun yang telah ditentukan dengan data suhu permukaan laut hasil klasifkasi Citra Satelit Landsat 8 TIRS pada koordinat dan titik stasiun yang sama. Selain itu perhitungan validasi data juga digunakan dalam validasi data arus permukaan pasang surut pemodelan hidrodinamika dan arus permukaan lapangan.

Chai dan Draxler (2014) menyatakan bahwa metode RMSE (Root Mean Square Eror) dapat digunakan untuk mengerahui nilai eror dari data lapangan dan data hasil peramalan.

$R M S E=\sqrt{\frac{1}{n} \sum_{i=1}^{n} e_{i}^{2}}$

Dimana $\mathrm{n}$ adalah jumlah data dan $\mathrm{e}_{\mathrm{i}}{ }^{2}$ adalah hasil pengolahan data dikurangi dengan nilai sebenarnya yang merupakan data lapangan. 


\section{HASIL DAN PEMBAHASAN}

Data Citra Landsat-8 perekaman Mei 2019 pada path/row 123/64 yang telah diolah pada software ER Mapper 7.0 didapatkan hasil sebaran suhu permukaan laut secara horizontal akibat limbah air bahang PT PLN Sektor Pembangkitan Tarahan. Pemetaan suhu permukaan laut dinyatakan dalam satuan derajat Celsius $\left({ }^{\circ} \mathrm{C}\right)$. Nilai suhu maksimum yang dihasilkan sebesar $33,5^{\circ} \mathrm{C}$ terdapat pada perairan di sekitar mulut outlet pembuangan air bahang dan suhu minimum adalah $29,4^{\circ} \mathrm{C}$ yang merupakan suhu perairan normal di perairan sekitar PLTU Tarahan Lampung Selatan.

Klasifikasi suhu permukaan laut yang terdapat pada perairan dibagi menjadi lima kelas dengan interval $1^{\circ} \mathrm{C}$ agar mudah dilakukan analisa, hasilnya ditampilkan pada Gambar 2. Suhu terendah diwakili warna biru dengan rentang suhu $(28,5-29,5){ }^{\circ} \mathrm{C}$, warna biru muda mewakili suhu $(29,5-30,5)^{\circ} \mathrm{C}$, warna hijau muda mewakili suhu $(30,5-31,5)^{\circ} \mathrm{C}$, warna jingga mewakili suhu $(31,5-32,5)^{\circ} \mathrm{C}$ dan terakhir warna merah mewakili suhu tertinggi dengan rentang $(32,5-33,5)^{\circ} \mathrm{C}$. Gambar 2 merupakan hasil pengolahan dari data suhu permukaan laut pengambilan secara langsung (Gambar 3), sedangkan Tabel 1 menunjukkan nilai tingkat kesalahan data suhu permukaan laut antara pengukuran suhu lapangan dengan citra Landsat-8.

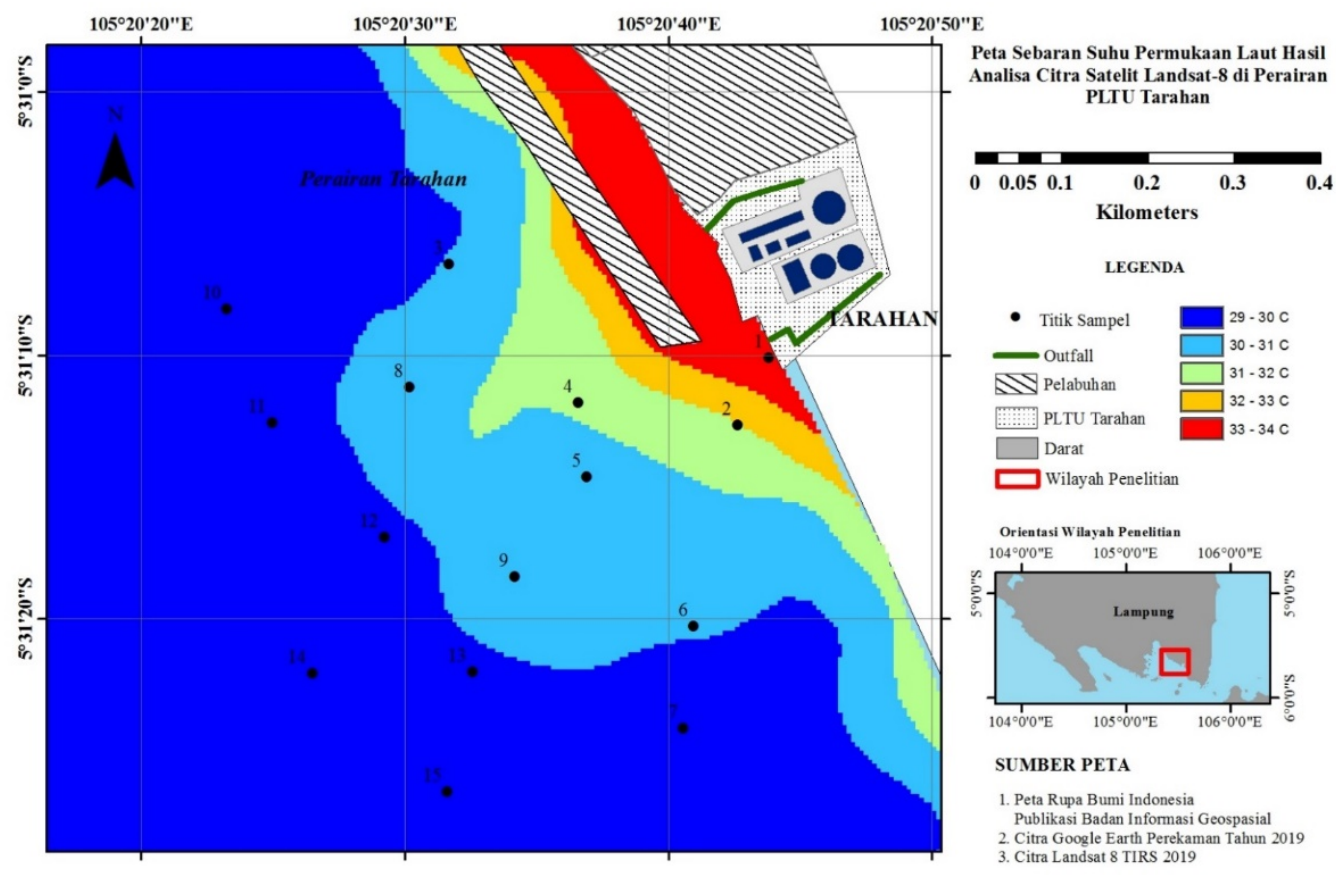

Gambar 2. Peta Sebaran Suhu Permukaan Laut Hasil Analisa Citra Landsat-8 


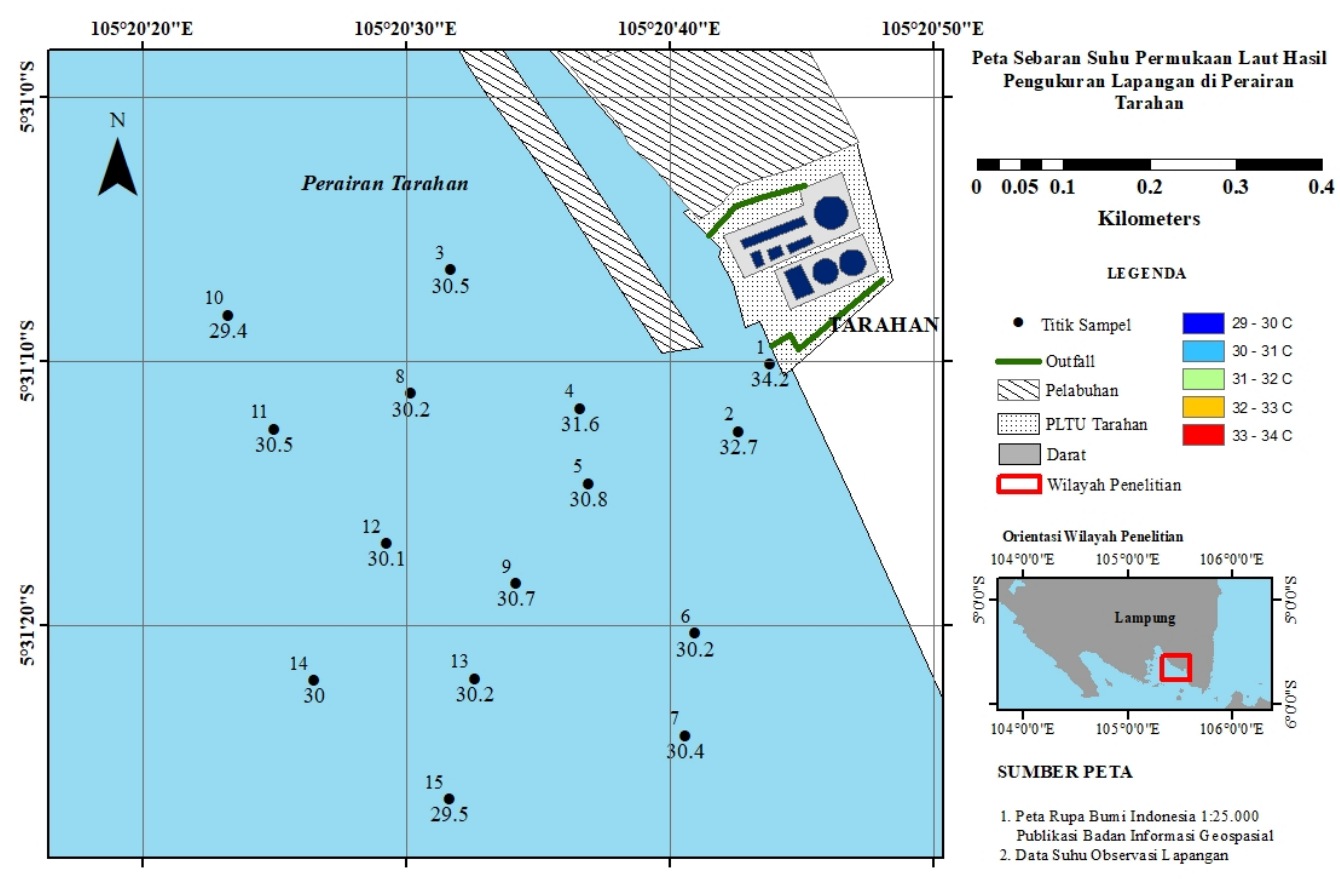

Gambar 3. Peta Sebaran Suhu Permukaan Laut Hasil Pengukuran Lapangan

Tabel 1. Nilai Kesalahan Suhu Permukaan Laut

\begin{tabular}{cccccc}
\hline $\begin{array}{c}\text { Titik } \\
\text { Sampel }\end{array}$ & $\begin{array}{c}\text { Suhu Pengukuran } \\
\text { Data Lapangan }\end{array}$ & $\begin{array}{c}\text { Suhu Citra } \\
\text { Landsat }-\boldsymbol{8}\end{array}$ & Selisih & SE \\
\hline 1 & 34.2 & 33.5 & 0.7 & 0.49 \\
2 & 32.7 & 32 & 0.7 & 0.49 \\
3 & 30.5 & 30.2 & 0.3 & 0.09 \\
4 & 31.6 & 31.2 & 0.4 & 0.16 \\
5 & 30.8 & 30.6 & 0.2 & 0.04 \\
6 & 30 & 30 & 0.2 & 0.04 \\
7 & 30.4 & 30.1 & 0.3 & 0.09 \\
8 & 30.2 & 30.5 & -0.3 & 0.09 \\
9 & 30.7 & 30.4 & 0.3 & 0.09 \\
10 & 29.4 & 29.6 & -0.2 & 0.04 \\
11 & 30.5 & 29.6 & 0.9 & 0.81 \\
12 & 30.1 & 29.5 & 0.6 & 0.36 \\
13 & 30.2 & 29.7 & 0.5 & 0.25 \\
14 & 30 & 29.3 & 0.7 & 0.49 \\
15 & 29.5 & 29.4 & 0.1 & 0.01 \\
\hline
\end{tabular}


menunjukan adanya selisih nilai besaran suhu permukaan laut di setiap stasiun, hal tersebut menunjukan adanya error di tiap stasiun. Hasil verifikasi data pengambilan lapangan dengan data hasil citra memiliki nilai rata-rata kesalahan atau Root Mean Squared Error (RMSE) sebesar 0,329. Nilai tersebut menunjukan bahwa akurasi yang didapat termasuk baik sebagaimana disebutkan oleh Parmadi dan Sukojo (2016) yang menyatakan bahwa apabila hasil perhitungan RMSE $\leq 1$ maka akurasinya semakin baik.

\section{Arus Permukaan}

Berdasarkan pengolahan pemodelan yang terdapat dalam perangkat lunak dengan memasukkan data batimetri dan garis pantai didapatkan simulasi model hidrodinamik dua dimensi melalui modul Mike 21 Hydrodynamic (HD). Hasil yang didapatkan berupa vektor arus dan kecepatan arus yang digambarkan dengan nilai panjang atau pendek suatu vektor dan arah pergerakan arus. Pengolahan dan penyajian data arus permukaan berdasarkan waktu pengambilan data in situ yaitu pada 10 Mei 2019 pukul 14.00 WIB.

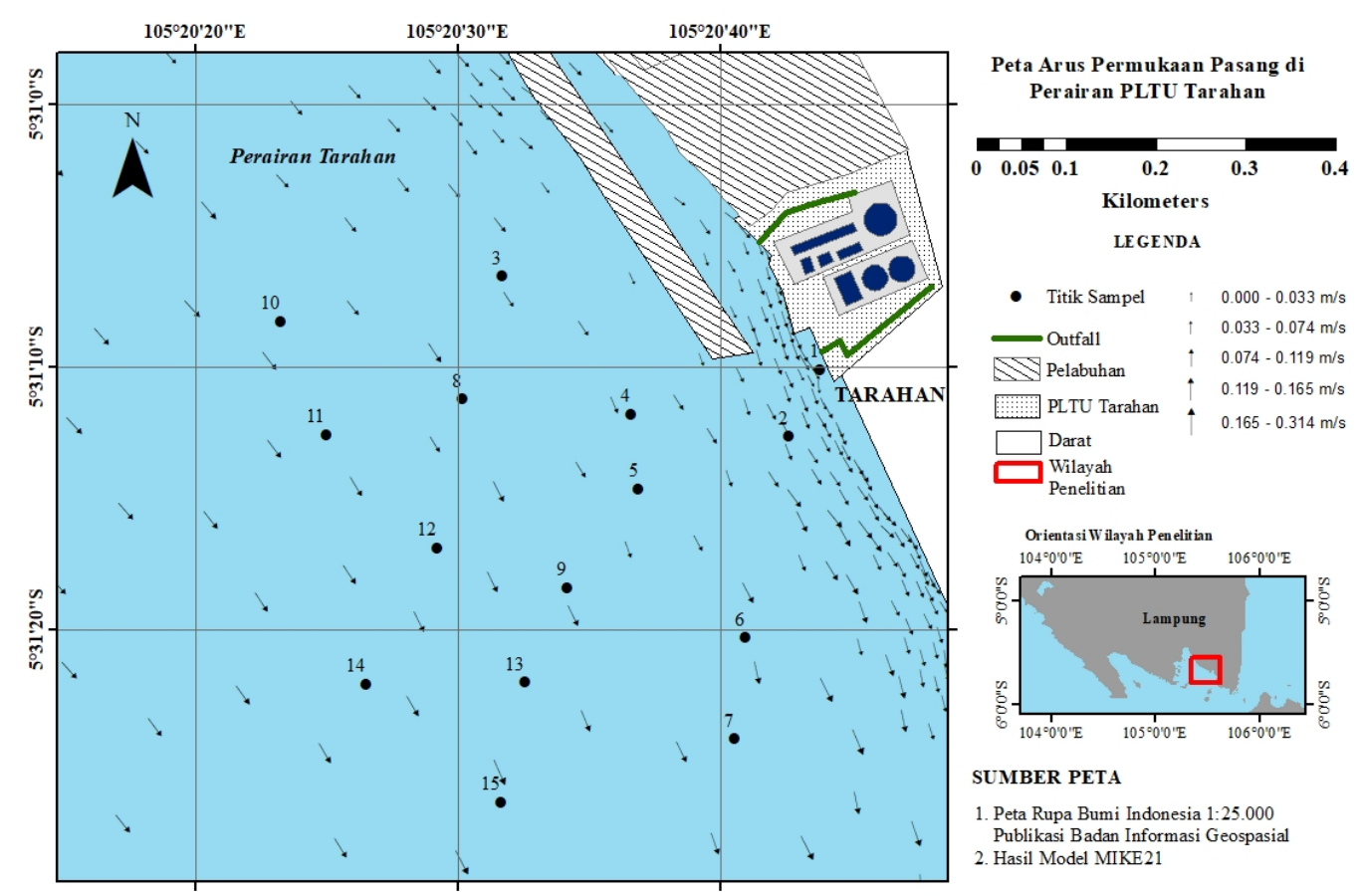

Gambar 4. Peta Hasil Model Arus di Perairan Tarahan Lampung Selatan

Dari hasil tersebut didapatkan bahwa perairan tersebut memiliki suhu berkisar dari $28,50^{\circ} \mathrm{C}$ hingga $33,50^{\circ} \mathrm{C}$. Pengklasifikasian suhu dilakukan dari suhu terendah hingga tertinggi. Suhu terendah berada pada rentang $28,50-29,50^{\circ} \mathrm{C}$ dan dilambangkan dengan warna biru tua. Suhu terendah menunjukan tidak adanya pengaruh dari pembuangan limbah air panas PLTU. Sedangkan suhu tertinggi dilambangkan dengan warna merah tua dengan rentang $32,5-33.5^{\circ} \mathrm{C}$. Tingginya suhu pada data ini menunjukan bahwa adanya pengaruh yang cukup besar dari limbah air panas PLTU Tarahan.

Titik sampel 1 berada di dekat outfall PLTU dengan suhu sebesar $34,2^{\circ} \mathrm{C}$ selanjutnya titik sampel 2 memiliki suhu sebesar $32^{\circ} \mathrm{C}$ yang masih berada di dekat outfall, titik 4 memiliki suhu sebesar $31,2^{\circ} \mathrm{C}$ karena masih berada segaris dengan outfall. Sementara itu titik 3 yang berada di arah barat laut dari outfall memiliki suhu sebesar $30,2^{\circ} \mathrm{C}$. Titik sampel 8 dan 5 memiliki suhu $30,5^{\circ} \mathrm{C}$ dan $30,6^{\circ} \mathrm{C}$ dan titik sampel 9 dan 6 suhu sebesar $30,4^{\circ} \mathrm{C}$ dan $30^{\circ} \mathrm{C}$. Keempat titik sampel yang telah disebutkan di atas masih terpengaruh oleh air bahang PLTU, sementara itu titik 7 sebesar $30,1^{\circ} \mathrm{C}$ dan titik 13 sebesar $29,7^{\circ} \mathrm{C}$ sudah mengalami penurunan karena wilayah perairan yang sudah mulai bercampur dengan perairan sekitar.Titik 10 sebesar $29,6{ }^{\circ} \mathrm{C}$, Titik 11 sebesar $29,6{ }^{\circ} \mathrm{C}$, Titik 12 sebesar $29,5^{\circ} \mathrm{C}$, Titik 14 sebesar $29,3{ }^{\circ} \mathrm{C}$, dan Titik 15 sebesar $29,4{ }^{\circ} \mathrm{C}$ sudah tidak terpengaruhi air bahang karena cukup jauh dari outfall. Selaras dengan pernyataan 
Nontji (1987) dalam Ismayanti (2013) yang menyatakan bahwa permukaan laut perairan Indonesia berkisar antara $28^{\circ} \mathrm{C}$ hingga $31^{\circ} \mathrm{C}$, kecuali perairan daerah sekitar sekitar pembuangan limbah industri atau pembangkit yang dapat mencapai $37^{\circ} \mathrm{C}$.

Persebaran suhu air panas menuju tenggara memiliki luasan sebesar 39 hektar dan berjarak 1,12 kilometer ke arah tenggara dari outfall. Berdasarkan hasil data pengolahan citra Landsat 8 TIRS menunjukan suhu tertinggi sebesar $33,4^{\circ} \mathrm{C}$. Hal ini dapat terjadi karena pada bulan Mei termasuk ke dalam musim peralihan satu. Pada musim ini merupakan periode awal musim kemarau, di mana keadaan perairan akan dipengaruhi oleh intensitas curah hujan yang tidak terlalu banyak yang kemudian akan menyebabkan perairan terasa hangat (Yananto dan Sibarani, 2016).

Berdasarkan hasil pengolahan data citra landsat dan model dari Mike 21 serta hasil pengambilan data arus lapangan menunjukan bahwa sebaran suhu permukaan laut yang dipengaruhi oleh limbah air panas bergerak menuju ke arah tenggara, hal tersebut dikarenakan pada periode Maret - Mei arus di perairan Lampung bergerak menuju ke arah tenggara (Rahmawitri, 2016). Pergerakan arus ke arah tenggara membuat nilai suhu permukaan laut semakin kecil. Suhu mengalami perubahan secara perlahan-lahan dari daerah pantai menuju laut lepas. Karena adanya perbedaan kedalaman dan juga pengaruh suhu lingkungan sekitar dapat mempengaruhi berkurangnya nilai suhu menjadi rendah.

\section{KESIMPULAN}

Sebaran panas air di depan PLTU Tarahan membentuk pola setengah busur dengan luasan sebesar 39 hektar dan berjarak 1,12 kilometer ke arah tenggara dari outfall. Nilai suhu di dekat outfall sebesar $33,5{ }^{\circ} \mathrm{C}$ sedangkan suhu air yang tidak terpengaruh sebesar $29,4^{\circ} \mathrm{C}$.

\section{DAFTAR PUSTAKA}

Bambang, T. Sayidah, Sulma. dan Syarif. 2011. Study of Sea Surface Temperature (SST) using Landsat-7 ETM (In Comparison with Sea Surface Temperature of NOAA-12 AVHRR). LAPAN Indonesia (Lembaga Penerbangan dan Antariksa Indonesia, Jakarta.

Ismayanti, Q, Helmi, M., Rochaddi, B. 2013. Kajian Spasial Suhu Permukaan Laut Akibat Air Bahang PLTU Paiton Menggunakan Saluran Termal Satelit Landsat 7/Etm+ Di Pantai Bhinor Kabupaten Probolinggo Jawa Timur. Jurnal Oseanografi. 2(1): 49-56

Parmadi, W.T dan Sukojo, B., M. 2016. Analisa Ketelitian Geometric Citra Pleiades Sebagai Penunjang Peta Dasar RDTR: (Studi Kasus: Wilayah Kabupaten Bangkalan, Jawa Timur). Jurnal Teknik ITS., 5(2): 2337-3539.

Rahmawitri, H., Agus Saleh A.,Sri Suryo S. 2016. Pola Sirkulasi dan Variabilitas Arus diPerairan Selat Sunda. Jurnal Kelautan Nasional., 11(3).

Wibowo, Mardi dan Velly Asvalantina. 2018. Kajian Dispersi Panas Akibat Air Limbah Rencana Pembangunan PLTU Kuala Tungkal Provinsi Jambi. BPPT. Jakarta

USGS. 2019. Landsat 8 (L8) Science Data Users Handbook, LSDS-1574. (5). 60-79

Yananto, A dan Sibarani, R. 2016. Analisis Kejadian El Nino dan Pengaruhnya Terhadap Intensitas Curah Hujan di Wilayah Jabodetabek (Studi Kasus : Periode Puncak Musim Hujan Tahun 2015/2016). Jurnal Sains \& Teknologi Modifikasi Cuaca. 17. (65). 